\title{
Effects of Immersion Time and 5-Phenyl-1H-tetrazole on the Corrosion and Corrosion Mitigation of Cobalt Free Maraging Steel in 0.5 M Sulfuric Acid Pickling Solutions
}

\author{
El-Sayed M. Sherif ${ }^{1,2}$ and Asiful H. Seikh ${ }^{1}$ \\ ${ }^{1}$ College of Engineering, King Saud University, P.O. Box 800, Riyadh 11421, Saudi Arabia \\ ${ }^{2}$ Electrochemistry and Corrosion Laboratory, Department of Physical Chemistry, National Research Centre (NRC), Dokki, \\ Cairo 12622, Egypt
}

Correspondence should be addressed to El-Sayed M. Sherif; esherif@ksu.edu.sa

Received 3 September 2013; Accepted 7 November 2013

Academic Editor: Henryk Kozlowski

Copyright (C) 2013 El-S.M. Sherif and A. H. Seikh. This is an open access article distributed under the Creative Commons Attribution License, which permits unrestricted use, distribution, and reproduction in any medium, provided the original work is properly cited.

\begin{abstract}
The effect of exposure time and 5-phenyl-1H-tetrazole on the corrosion and corrosion mitigation of cobalt free maraging steel in $0.5 \mathrm{M} \mathrm{H}_{2} \mathrm{SO}_{4}$ pickling solutions has been reported using electrochemical and spectroscopic investigations. Potentiodynamic polarization data showed that the increase of immersion time from $0 \mathrm{~min}$ to $120 \mathrm{~min}$ increases the corrosion rate and decreases the polarization resistance of the maraging steel. On the other hand, the addition of PHTA and the increase of its concentration decrease all the corrosion parameters of the steel at all exposure test periods. Electrochemical impedance spectroscopy measurements agreed with the obtained polarization data. Scanning electron spectroscopy and energy dispersive X-ray investigations confirmed that the inhibition of the steel corrosion is achieved via the adsorption of the PHTA molecules onto the steel precluding its surface from being dissolved.
\end{abstract}

\section{Introduction}

Maraging steels are a generic class of ultrahigh strength steels that are hardened by a metallurgical reaction that does not involve carbon [1]. Maraging refers to the ageing of martensite, which is easily obtained at normal cooling rates due to the high nickel content [2]. The ultrahigh strength of maraging steels results from the precipitation of intermetallic compounds during the ageing process at about $480^{\circ} \mathrm{C}$ [3-6]. Maraging steels have been widely used in many tooling applications including missile and rocket motor cases, aircraft, aerospace, wind tunnel models, landing gear components, high performance shafting, gears, fasteners, and nuclear and gas turbine applications.

The corrosion and corrosion protection of maraging steels in different media have been investigated by many researchers [1-3, 7-9]. It has been reported [2] that maraging steels show better corrosion resistance in acidic solutions compared to tempered martensite alloy steels. The corrosion of maraging steels in acidic solutions results mainly during the acid cleaning, where the scales and corrosion products that form on the steel surface and cause a negative effect on the performance of the steel equipment must be cleaned using an acidic pickling solution. In this regard, sulfuric acid is one of the most aggressive acids for iron and its alloys and is often used during cleaning, pickling, descaling, acidizing, and so forth $[2,10]$.

It is well known that the corrosion inhibitors are added with the pickling solutions to mitigate the aggressive attack of the acid solution to the surface of the structure to be cleaned $[6,11,12]$. Organic compounds containing polar groups including nitrogen, sulfur, and oxygen and heterocyclic compounds with polar functional groups have been reported to be good corrosion inhibitors [13-20]. The inhibiting action of these organic compounds is usually attributed to their interactions with the metal surface via their adsorption [21].

The aim of the present work was to report the effects of exposure times, namely, 0,60 , and $120 \mathrm{~min}$, on the corrosion 
of maraging steel in the freely aerated stagnant $0.5 \mathrm{M} \mathrm{H}_{2} \mathrm{SO}_{4}$ solutions. The aim was also extended to the study of the effect of 5-phenyl-1H-tetrazole (PHTA) on the inhibition of the corrosion of maraging steel in the $0.5 \mathrm{M} \mathrm{H}_{2} \mathrm{SO}_{4}$ pickling solution after the aforementioned exposure times at room temperature.

\section{Experimental Procedures}

2.1. Chemicals, Materials, and Electrochemical Cell. A stoke solution of $2.0 \mathrm{M}$ of sulfuric acid was prepared from an asreceived acid bottle $\left(96 \% \mathrm{H}_{2} \mathrm{SO}_{4}\right.$, Merck); the test solution, $0.5 \mathrm{M}$, was further prepared from the stock by dilution. A maraging steel electrode with a square shape and surface dimensions of $1 \times 1 \mathrm{~cm}$ was used. This steel electrode was iron based alloy that had $11.16 \% \mathrm{Ni}, 1.76 \% \mathrm{Mo}, 1.11 \% \mathrm{~W}, 0.641 \%$ $\mathrm{Ti}, 0.102 \% \mathrm{Al}, 0.0325 \% \mathrm{C}$, and $0.004 \% \mathrm{Cr}$ in its chemical compositions.

A conventional electrochemical cell with a three-electrode configuration was used; the maraging steel rod, a platinum foil, and an $\mathrm{Ag} / \mathrm{AgCl}$ electrode (in the saturated $\mathrm{KCl}$ ) were used as the working, counter, and reference electrodes, respectively. Before measurement, the working electrode was ground successively with metallographic emery paper of increasing fineness of up to 1200 grit, then cleaned using doubly distilled water, degreased with acetone, washed using doubly distilled water again, and finally dried with dry air.

2.2. Electrochemical Measurement Techniques. An Autolab Potentiostat (PGSTAT20 computer controlled) operated by the General Purpose Electrochemical Software (GPES) version 4.9 was used to perform the electrochemical experiments. The potentiodynamic polarization curves were obtained by scanning the potential in the forward direction from $-500 \mathrm{mV}$ to $-100 \mathrm{mV}$ versus $\mathrm{Ag} / \mathrm{AgCl}$ at a scan rate of $1 \mathrm{mV} / \mathrm{s}$. The electrochemical impedance spectroscopy (EIS) tests were performed at corrosion potentials over a frequency range of $100 \mathrm{kHz}$ to $100 \mathrm{mHz}$, with an ac wave of $\pm 5 \mathrm{mV}$ peakto-peak overlaid on a dc bias potential, and the impedance data were collected using Powersine software at a rate of 10 points per decade change in frequency. All electrochemical experiments were carried out on a fresh surface of the steel and a new test solution (in a cell that contains $200 \mathrm{~mL}$ of the freely aerated stagnant $0.5 \mathrm{M} \mathrm{H}_{2} \mathrm{SO}_{4}$ ) at room temperature.

2.3. Scanning Electron Microscope (SEM) and Energy Dispersive X-Ray (EDX). The SEM images were obtained by using a JEOL model JSM-6610LV (Japanese made) scanning electron microscope with an energy dispersive X-ray analyzer attached for acquiring the EDX analysis.

\section{Results and Discussion}

3.1. Potentiodynamic Polarization Measurements. The potentiodynamic polarization curves obtained for the maraging steel after 0 min immersion in $0.5 \mathrm{M} \mathrm{H}_{2} \mathrm{SO}_{4}$ solutions containing (1) 0.0 M PHTA, (2) $1.0 \mathrm{mM}$ PHTA, and (3) $5.0 \mathrm{mM}$ PHTA, respectively, are shown in Figure 1. In order to study

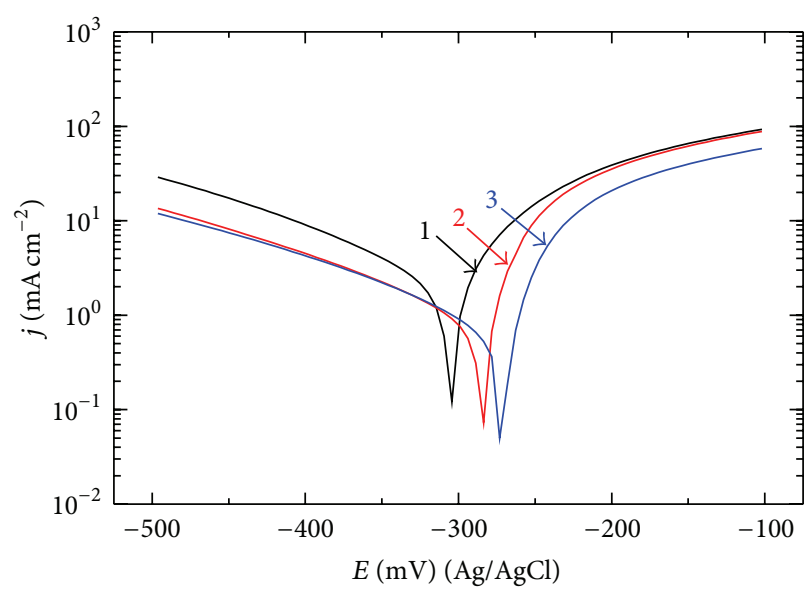

FIGURE 1: Potentiodynamic polarization curves obtained for the maraging steel after $0 \mathrm{~min}$ immersion in $0.5 \mathrm{M} \mathrm{H}_{2} \mathrm{SO}_{4}$ solutions containing (1) 0.0 M PHTA, (2) $1.0 \mathrm{mM}$ PHTA, and (3) $5.0 \mathrm{mM}$ PHTA, respectively.

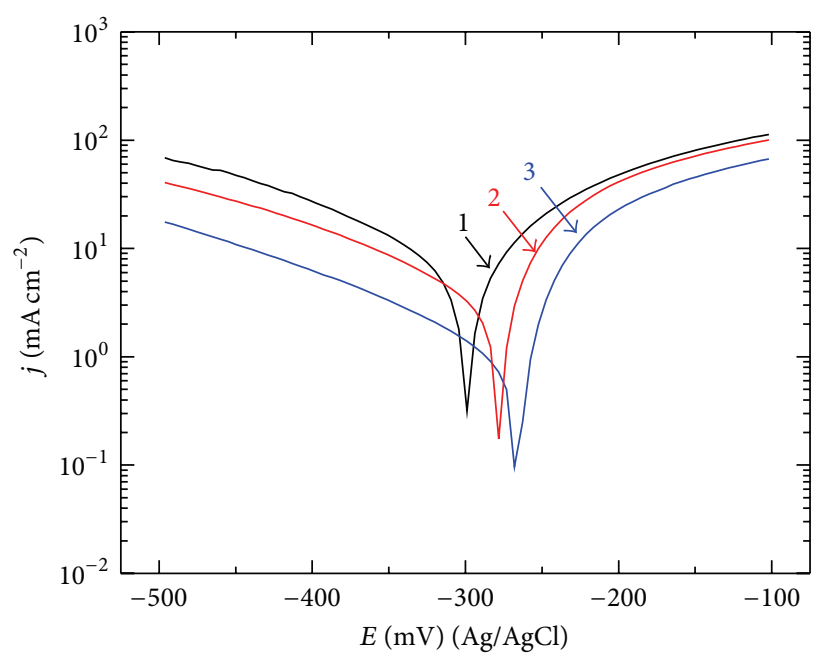

FIGURE 2: Potentiodynamic polarization curves for the maraging steel after $60 \mathrm{~min}$ immersion in $0.5 \mathrm{M} \mathrm{H}_{2} \mathrm{SO}_{4}$ solutions containing (1) $0.0 \mathrm{M}$ PHTA, (2) $1.0 \mathrm{mM}$ PHTA, and (3) $5.0 \mathrm{mM}$ PHTA, respectively.

the effect of exposure time as well as the concentration of PHTA on the corrosion and corrosion inhibition of the maraging steel, the same technique was used after $60 \mathrm{~min}$ and $120 \mathrm{~min}$ at the same concentration of PHTA and the curves are shown in Figures 2 and 3, respectively. Corrosion parameters, that is, corrosion potential $\left(E_{\text {Corr }}\right)$, corrosion current density $\left(j_{\text {Corr }}\right)$, cathodic $\left(\beta_{c}\right)$ and anodic $\left(\beta_{a}\right)$ Tafel slopes, polarization resistance $\left(R_{p}\right)$, corrosion rate $\left(R_{\text {Corr }}\right)$, and the percentage of the inhibition efficiency (IE\%) obtained from the PHTA different concentrations, which were obtained from the polarization data are listed in Table 1 . The values of these parameters were calculated as reported in our previous studies $[5,6]$.

It is clearly seen from Figure 1 and Table 1 that the presence and the increase of the PHTA concentration decrease 
TABLE 1: Corrosion parameters obtained from the potentiodynamic polarization curves shown in Figures 1, 2, and 3 for maraging steel electrode that has been immersed for different exposure intervals in $0.5 \mathrm{M} \mathrm{H}_{2} \mathrm{SO}_{4}$ containing different PHTA concentrations.

\begin{tabular}{|c|c|c|c|c|c|c|c|}
\hline \multirow[b]{2}{*}{ Medium } & \multicolumn{7}{|c|}{ Parameter } \\
\hline & $\begin{array}{c}\beta_{c} \\
\left(\mathrm{mVdec}^{-1}\right)\end{array}$ & $\begin{array}{l}E_{\text {Corr }} \\
(\mathrm{mV})\end{array}$ & $\begin{array}{c}j_{\text {Corr }} \\
\left(\mu \mathrm{A} \mathrm{cm}^{-2}\right)\end{array}$ & $\begin{array}{c}\beta_{a} \\
\left(\mathrm{mVdec}^{-1}\right)\end{array}$ & $\begin{array}{c}R_{p} \\
\left(\Omega \mathrm{cm}^{2}\right)\end{array}$ & $\begin{array}{c}R_{\text {Corr }} \\
\left(\mathrm{mmy}^{-1}\right)\end{array}$ & $\begin{array}{l}\text { IE } \\
(\%)\end{array}$ \\
\hline $0.5 \mathrm{M} \mathrm{H}_{2} \mathrm{SO}_{4}(0 \mathrm{~min})$ & -135 & -300 & 1900 & 35 & 0.011 & 22.09 & $\overline{-}$ \\
\hline+1.0 mM PHTA (0 min) & -135 & -283 & 880 & 28 & 0.017 & 10.23 & 54 \\
\hline +5.0 mM PHTA (0 min) & -140 & -270 & 670 & 30 & 0.025 & 7.79 & 65 \\
\hline $0.5 \mathrm{M} \mathrm{H}_{2} \mathrm{SO}_{4}(60 \mathrm{~min})$ & -100 & -300 & 3300 & 48 & 0.012 & 38.37 & - \\
\hline$+1.0 \mathrm{mM}$ PHTA (60 min) & -120 & -295 & 1450 & 50 & 0.023 & 16.86 & 56 \\
\hline +5.0 mM PHTA (60 min) & -105 & -265 & 1050 & 55 & 0.028 & 12.21 & 68 \\
\hline $0.5 \mathrm{M} \mathrm{H}_{2} \mathrm{SO}_{4}(120 \mathrm{~min})$ & -95 & -290 & 4300 & 55 & 0.013 & 49.99 & - \\
\hline +1.0 mM PHTA (120 min) & -100 & -280 & 1720 & 58 & 0.029 & 17.00 & 60 \\
\hline +5.0 mM PHTA (120 min) & -122 & -275 & 1190 & 60 & 0.039 & 13.84 & 72 \\
\hline
\end{tabular}

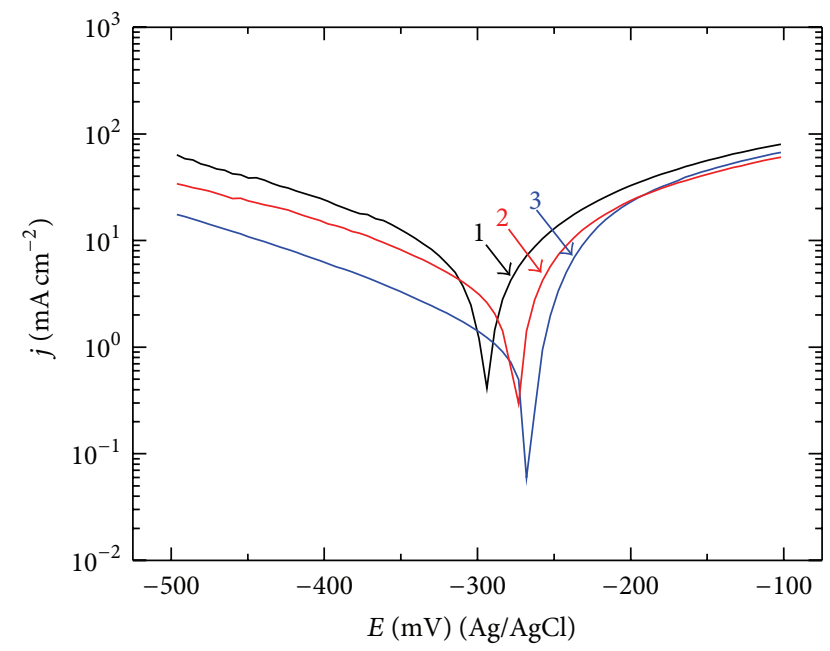

Figure 3: Potentiodynamic polarization curves for the maraging steel after $120 \mathrm{~min}$ immersion in $0.5 \mathrm{M} \mathrm{H}_{2} \mathrm{SO}_{4}$ solutions containing (1) 0.0 M PHTA, (2) $1.0 \mathrm{mM}$ PHTA, and (3) $5.0 \mathrm{mM}$ PHTA, respectively.

the cathodic and anodic currents and the values of $j_{\text {Corr }}$ and $R_{\text {Corr }}$, while they increase the values of $R_{p}$ and shifts the values of $E_{\text {Corr }}$ to the less negative values. Decreasing the cathodic and anodic currents in the presence of PHTA molecules is due to the decrease of the cathodic and anodic reactions on the steel surface, which in turn decrease the corrosion of the steel through minimizing the values of $j_{\text {Corr }}$ and $R_{\text {Corr }}$ as well as increasing the corrosion resistance by increasing the values of $R_{p}$.

Increasing the immersion time to $60 \mathrm{~min}$ (Figure 2) and further to $120 \mathrm{~min}$ (Figure 3 ) led to increasing the corrosion of the maraging steel, especially in the absence of PHTA, as confirmed by the increase of the values of $j_{\text {Corr }}$ and $R_{\text {Corr }}$ and the decrease of the $R_{p}$ values. This is because increasing the immersion increases the dissolution of steel under the aggressive action of the sulfuric acid solution. It has been reported [22] that the cathodic reaction for metals and alloys in sulfuric acid solutions is the hydrogen evolution according to the following equation:

$$
2 \mathrm{H}^{+}+2 \mathrm{e}^{-}=\mathrm{H}_{2}
$$

The electrons consumed at the cathode due to the hydrogen ion reduction are produced during the dissolution of iron of the alloy in the corrosive acid medium through the anodic reaction as follows:

$$
\mathrm{Fe}=\mathrm{Fe}^{2+}+2 \mathrm{e}^{-}
$$

Increasing the immersion time increases the dissolution of the maraging steel via the corrosion of iron (2), under the continuous attack of sulfuric acid to the alloys surface, which does not allow the alloy to form any oxide and/or corrosion products that can reduce the corrosion. Increasing the applied potential in the less negative direction further facilitates the corrosion of steel as indicated by the increase of the anodic currents with potential and with the increase of immersion time.

The addition of PHTA and the increase of its concentration decreased the corrosion parameters for the steel. Where, the values of $j_{\text {Corr }}$ and $R_{\text {Corr }}$ decrease and the values of $R_{p}$ and IE\% increase with increasing PHTA content and with increasing the exposure time of the steel from 0 to $120 \mathrm{~min}$ before the polarization measurements. This was further confirmed by the polarization data that are listed in Table 1 and indicates that PHTA is a good corrosion inhibitor for the maraging steel in $0.5 \mathrm{M} \mathrm{H}_{2} \mathrm{SO}_{4}$ solution and its efficiency increases with the increase of its concentration and with the immersion time.

3.2. SEM Micrographs and EDX Profile Analysis. In order to see whether the PHTA molecules are adsorbed on the surface of the maraging steel in the test solution, $0.5 \mathrm{M} \mathrm{H}_{2} \mathrm{SO}_{4}$, scanning electron microscope (SEM) image was taken on a dry steel surface that was immersed for $120 \mathrm{~min}$ in a solution containing $0.5 \mathrm{M} \mathrm{H}_{2} \mathrm{SO}_{4}$ and $1.0 \mathrm{mM}$ PHTA and the micrograph is depicted in Figure 4(a). The corresponding energy dispersive X-ray analyzer (EDX) profiles that were taken for two different areas on the image are respectively 
TABLE 2: EIS parameters obtained by fitting the Nyquist plots shown in Figures 5, 6, and 7 with the equivalent circuit shown in Figure 8 for the maraging steel in sulfuric acid solutions containing different concentrations of PHTA.

\begin{tabular}{|c|c|c|c|c|c|c|}
\hline \multirow[b]{2}{*}{ Solution } & \multicolumn{6}{|c|}{ Parameter } \\
\hline & $R_{S} / \Omega \mathrm{cm}^{2}$ & $Y_{\mathrm{Q}} / \mathrm{F} \mathrm{cm}^{-2}$ & $n$ & $R_{P 1} / \Omega \mathrm{cm}^{2}$ & $R_{P 2} / \Omega \mathrm{cm}^{2}$ & $L / H$ \\
\hline $0.5 \mathrm{M} \mathrm{H}_{2} \mathrm{SO}_{4}(0 \mathrm{~min})$ & 1.46 & 0.01214 & 0.83 & 7.34 & 1.74 & 0.32 \\
\hline$+1.0 \mathrm{mM}$ PHTA $(0 \mathrm{~min})$ & 1.65 & 0.00455 & 0.80 & 8.56 & 2.46 & 1.37 \\
\hline$+5.0 \mathrm{mM}$ PHTA $(0 \mathrm{~min})$ & 1.94 & 0.00213 & 0.77 & 12.94 & 3.57 & 3.74 \\
\hline $0.5 \mathrm{M} \mathrm{H}_{2} \mathrm{SO}_{4}(60 \mathrm{~min})$ & 1.33 & 0.04882 & 0.80 & 5.96 & 1.29 & 0.293 \\
\hline+1.0 mM PHTA (60 min) & 1.48 & 0.00551 & 0.79 & 7.28 & 2.34 & 1.181 \\
\hline$+5.0 \mathrm{mM}$ PHTA $(60 \mathrm{~min})$ & 1.78 & 0.00351 & 0.76 & 9.88 & 3.14 & 2.468 \\
\hline $0.5 \mathrm{M} \mathrm{H}_{2} \mathrm{SO}_{4}(120 \mathrm{~min})$ & 1.05 & 0.06054 & 0.94 & 3.97 & 1.18 & 0.049 \\
\hline +1.0 mM PHTA (120 min) & 1.24 & 0.01963 & 0.81 & 5.73 & 2.17 & 1.131 \\
\hline +5.0 mM PHTA (120 min) & 1.49 & 0.01674 & 0.76 & 7.91 & 2.92 & 2.139 \\
\hline
\end{tabular}
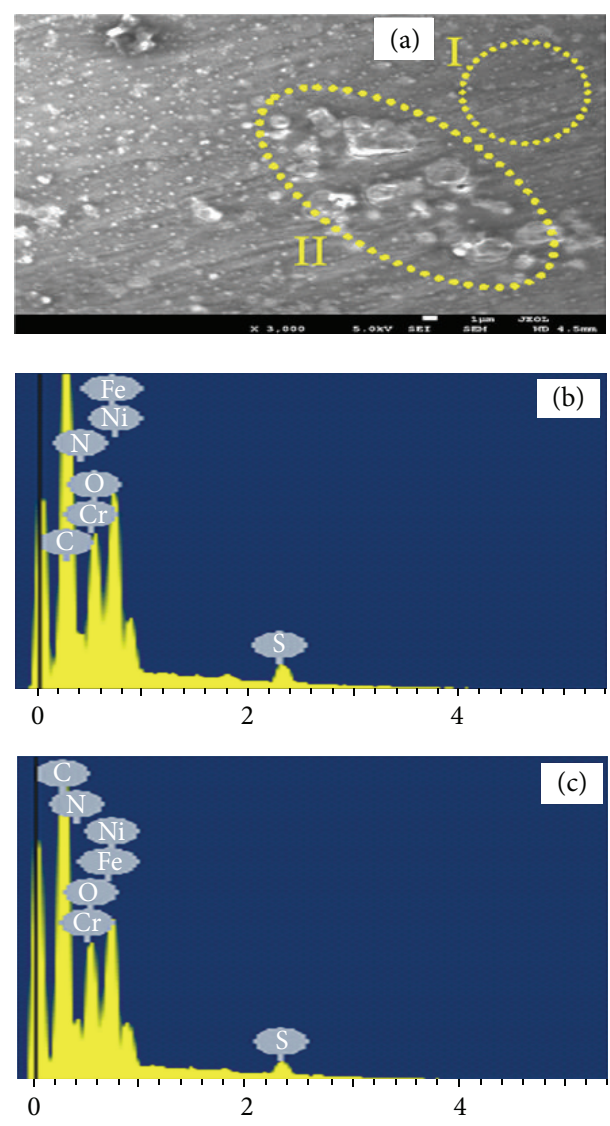

FIGURE 4: (a) SEM micrograph obtained from the maraging steel electrode after its immersion for $1 \mathrm{~h}$ in $0.5 \mathrm{M} \mathrm{H}_{2} \mathrm{SO}_{4}$ containing $1.0 \mathrm{mM}$ PHTA; (b) and (c) are the corresponding EDX profile analyses for the area I and area II shown on the micrograph, respectively.

shown in Figures 4(b) and 4(c). The SEM micrograph, Figure 4(a), indicates that the surface of steel at this condition is fully covered with an adsorbed layer, which is slightly thin at area I and thicker at area II. The atomic percentages of the elements found in area I and represented by the EDX profile shown in Figure 4(b) indicated that this area was $48.74 \%$ C,
$22.36 \% \mathrm{Fe}, 10.13 \% \mathrm{~N}, 9.81 \% \mathrm{O}, 4.38 \% \mathrm{Ni}, 2.32 \% \mathrm{~S}$, and $2.26 \%$ $\mathrm{Cr}$. On the other hand, the atomic percentages of the elements presented on the surface of area II that is depicted in the EDX profile analysis (Figure 4(c)) were $47.69 \% \mathrm{C}, 21.10 \% \mathrm{Fe}$, $13.27 \% \mathrm{~N}, 10.25 \% \mathrm{O}, 4.01 \% \mathrm{Ni}, 2.12 \% \mathrm{~S}$, and $1.55 \% \mathrm{Cr}$. The small amounts of $\mathrm{Fe}$ and $\mathrm{Ni}$ and the disappearance of Mo and $\mathrm{W}$, as well as the appearance of high percentages of $\mathrm{C}, \mathrm{O}, \mathrm{N}$, and $\mathrm{S}$, indicate that the investigated surface (area I and area II) is covered with an adsorbed layer of the PHTA organic compound. The presence of $\mathrm{N}$ and $\mathrm{S}$ on the tested surface confirmed that the decrease of corrosion rate of the steel in the presence of PHTA is due to the inhibition effectiveness of that compound in precluding the corrosion of the maraging steel. The higher percentages of $\mathrm{N}$ and $\mathrm{S}$ as well as the smaller values for $\mathrm{Fe}, \mathrm{Ni}$, and $\mathrm{Cr}$ in area II compared to area I reveal that the PHTA adsorbed layer is thicker in area II than in area I. SEM/EDX investigations thus confirm the polarization data that the presence of PHTA inhibits the corrosion of the cobalt free maraging steel in $0.5 \mathrm{M} \mathrm{H}_{2} \mathrm{SO}_{4}$ solution due to the adsorption of its molecules on the steel surface preventing it from being corroded easily.

3.3. Electrochemical Impedance Spectroscopy (EIS) Measurements. EIS is very important technique in studying corrosion and corrosion inhibition of metals and alloys in corrosive environments [23-25]. The EIS method has been successfully employed in explaining the inhibition of iron and steel alloys in aqueous media [23-27]. The EIS Nyquist plots obtained for the cobalt free maraging steel electrode at open circuit potential after 0 min immersion in $0.5 \mathrm{M} \mathrm{H}_{2} \mathrm{SO}_{4}$ containing (1) 0.0 PHTA, (2) $1.0 \mathrm{mM}$ PHTA, and (3) $5.0 \mathrm{mM}$ PHTA are depicted in Figure 5. The Nyquist plots obtained for the same electrode after increasing the immersion time to $60 \mathrm{~min}$ and further to $120 \mathrm{~min}$ at the same condition are shown in Figures 6 and 7, respectively. These Nyquist spectra were fitted to the best equivalent circuit model, $R(Q R)(R L)$, that is represented in Figure 8. The EIS parameters obtained by fitting the circuit shown in Figure 8 are listed in Table 2. The elements of the circuit can be identified according to the universal definition as follows; $R_{S}$ represents the solution resistance, $Q$ is the constant phase elements (CPEs), 


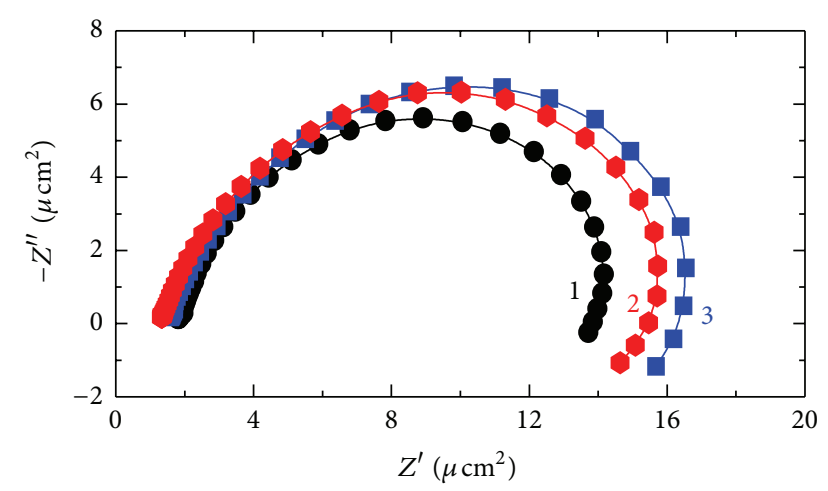

FIGURE 5: Nyquist plots for the maraging steel electrode at open circuit potential after $0 \mathrm{~min}$ immersion in $0.5 \mathrm{M} \mathrm{H}_{2} \mathrm{SO}_{4}$ containing (1) 0.0 PHTA, (2) $1.0 \mathrm{mM} \mathrm{PHTA}$, and (3) $5.0 \mathrm{mM}$ PHTA, respectively.

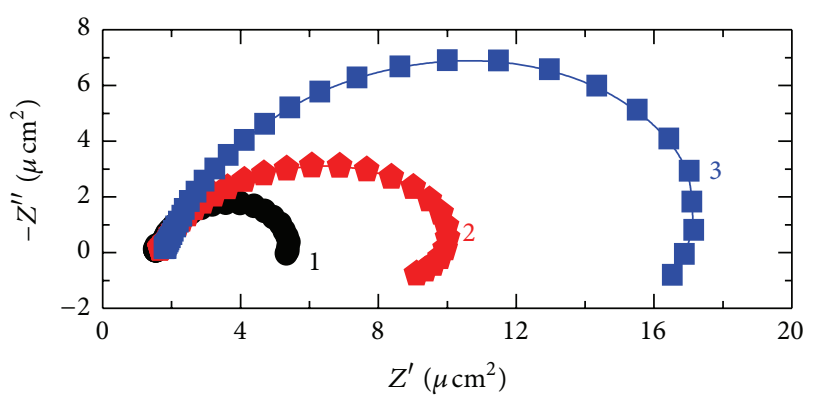

FIGURE 6: Nyquist plots for the maraging steel electrode at open circuit potential after $60 \mathrm{~min}$ immersion in $0.5 \mathrm{M} \mathrm{H}_{2} \mathrm{SO}_{4}$ containing (1) 0.0 PHTA, (2) 1.0 mM PHTA, and (3) 5.0 mM PHTA, respectively.

$R_{p 1}$ is polarization resistance and can be defined as the charge transfer resistance [28], $R_{p 2}$ is another polarization resistance, and $L$ is an inductance.

It is clearly seen from Figure 5 that the maraging steel in the sulfuric acid alone, curve 1, shows one semicircle whose diameter increases with the presence of $1.0 \mathrm{mM}$ PHTA, curve 2, and further with the increase of its concentration to $5.0 \mathrm{mM}$, curve 3 . The increase of the diameter of the shown semicircle is due to the inhibition of steel corrosion by the presence of PHTA and the increase of its content in the solution. The data recorded in Table 2 depicted also that the values of $R_{S}, R_{p 1}, R_{p 2}$, and $L$ increase, while the value of $Q$ (CPEs) decreases in the presence of PHTA and with the increase of its concentration. The increase of $R_{S}, R_{p 1}$, and $R_{p 2}$ reveals that the increased concentration of PHTA increases the solution and corrosion resistance of the maraging steel surface. The constant phase elements (CPEs, Q) with their $n$ values varied between 0.83 and 0.77 represent double layer capacitors with some pores; the CPEs decrease upon addition of PHTA and upon the increase in its concentration, which are expected to cover the charged surfaces reducing the capacitive effects [28].

Increasing the immersion time to 60 min (Figure 6) and further to $120 \mathrm{~min}$ (Figure 7) decreases the diameter of the semicircle whether PHTA is present or not. This indicates that the increase of immersion time increases the corrosion

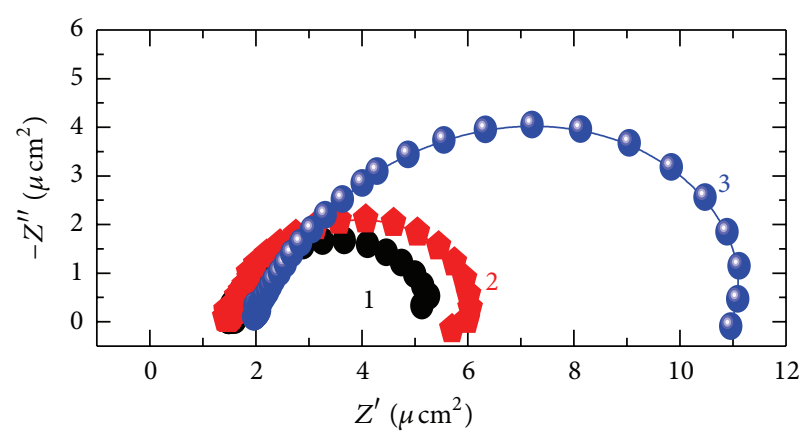

FIGURE 7: Nyquist plots for the maraging steel electrode at open circuit potential after 120 min immersion in $0.5 \mathrm{M} \mathrm{H}_{2} \mathrm{SO}_{4}$ containing (1) 0.0 PHTA, (2) 1.0 mM PHTA, and (3) 5.0 mM PHTA, respectively.

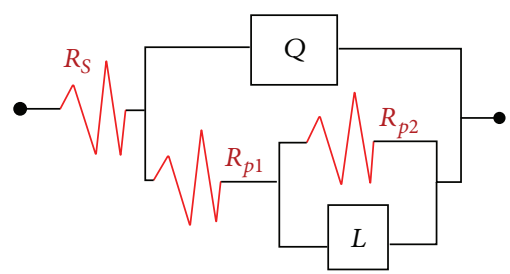

FIGURE 8: The equivalent circuit used to fit the experimental EIS data obtained for maraging steel after its immersion in the different concentrations of sulfuric acid.

parameters of the maraging steel in $0.5 \mathrm{M} \mathrm{H}_{2} \mathrm{SO}_{4}$ solution, where the values of the $R_{S}, R_{p 1}, R_{p 2}$ and $L$ remarkably increased and the values of $Y_{Q}$ decreased with increasing the immersion time. Similar effect was also recorded for the steel by the addition of PHTA and the increase of its concentrations. The EIS data was obtained in studying the effect of increasing PHTA contents and the period of the immersion time on the dissolution and corrosion mitigation of the maraging steel in the sulfuric acid, $0.5 \mathrm{M}$, solution. Both techniques proved that increasing the immersion time of maraging steel under investigation increases its corrosion and PHTA is a good corrosion inhibitor and its efficiency increases with the increase of its concentration for the used steel in $0.5 \mathrm{M} \mathrm{H}_{2} \mathrm{SO}_{4}$ solution.

\section{Conclusions}

The electrochemical dissolution of cobalt free maraging steel and its mitigation by PHTA after varied exposure periods of 0 , 60 , and 120 min of immersion in $0.5 \mathrm{M} \mathrm{H}_{2} \mathrm{SO}_{4}$ solution were reported. The study was carried out using potentiodynamic polarization and electrochemical impedance spectroscopy measurements and complemented by SEM and EDX investigations. Polarization curves showed that the increase of immersion time for the steel before measurement increases the values of $j_{\text {Corr }}$ and $R_{\text {Corr }}$ and decreases $R_{p}$ and shifts $E_{\text {Corr }}$ to the less negative values. The presence of PHTA and the increase of its concentration highly reduced the values of $j_{\text {Corr }}$ and $R_{\text {Corr }}$ and increased $R_{p}$ and IE\% values with a great shift in $E_{\text {Corr }}$ in the positive direction. Impedance spectra proved that the corrosion of the maraging steel increases with 
increasing the immersion time through decreasing the values of $R_{S}$ and $R_{p}$ resistance. On the other hand, the effect of PHTA molecules was found to increase with the increase of its concentration. SEM/EDX surface investigation confirmed that the mitigation of the steel corrosion is achieved by the adsorption of PHTA molecules onto the surface isolating and blocking its active sites and preventing it from dissolving in the harsh sulfuric acid pickling solution. Results together agree with each other and showed clearly that PHTA is a good corrosion inhibitor for the maraging steel in the solution under investigation and its efficiency increases with the increase of its concentration and the increase of the immersion time before measurement.

\section{Acknowledgment}

The authors extend their appreciation to the Deanship of Scientific Research at KSU for funding the work through the research group Project no. RGP-VPP-160.

\section{References}

[1] R. F. Decker, S. Floreen, and R. K. Wilson, "Maraging steel: recent developments and applications," in Proceedings of the Symposium of TMS Annual Meeting, pp. 1-38, Phoenix, Ariz, USA, 1988.

[2] T. Poornima, N. Jagannatha, and A. Nityananda Shetty, "Studies on corrosion of annealed and aged $18 \mathrm{Ni} 250$ grade maraging steel in sulphuric acid medium," Portugaliae Electrochimica Acta, vol. 28, no. 3, pp. 173-188, 2010.

[3] R. F. Decker, J. T. Eash, and A. J. Goldman, “18\% nickel maraging steel," ASM Transactions Quarterly, vol. 55, p. 58, 1962.

[4] B. S. Sanatkumar, J. Nayak, and A. N. Shetty, "Corrosion behavior of 18\% Ni M250 grade maraging steel under weld-aged condition in sulfuric acid medium," Chemical Engineering, vol. 199, p. 1610, 2012.

[5] E. M. Sherif and S.-M. Park, "Inhibition of copper corrosion in acidic pickling solutions by N-phenyl-1,4-phenylenediamine," Electrochimica Acta, vol. 51, no. 22, pp. 4665-4673, 2006.

[6] E. M. Sherif and S.-M. Park, "Effects of 2-amino-5-ethylthio1,3,4-thiadiazole on copper corrosion as a corrosion inhibitor in aerated acidic pickling solutions," Electrochimica Acta, vol. 51, no. 28, pp. 6556-6562, 2006.

[7] G. A. El-Mahdy, M. M. Hegaz, F. EL-Taib Heakal, H. E. Mahmoud, A. M. Fathy, and F. M. Sayed, "Electrochemical behavior of maraging steel in chloride containing environment," International Journal of Electrochemical Science, vol. 8, no. 2, p. 2816, 2013.

[8] Y. Jiang, Y. Y. Ai, and Q. T. Wang, "Study on corrosion resistance of 00Cr13Ni7Co5Mo4W maraging stainless steel in seawater," Applied Mechanics and Materials, vol. 274, pp. 402-405, 2013.

[9] Y. Y. Ai, Y. Jiang, and Q. T. Wang, "Effect of aging temperature on corrosion behaviors of maraging stainless steel in seawater," Applied Mechanics and Materials, vol. 274, pp. 419-422, 2013.

[10] P. Kumar and A. N. Shetty, "Electrochemical investigation on the corrosion of $18 \% \mathrm{Ni}$ M250 grade maraging steel under welded condition in sulfuric acid medium," Surface Engineering and Applied Electrochemistry, vol. 49, pp. 253-260, 2013.
[11] N. S. Patel, S. Jauhari, and G. N. Mehta, "Inhibitive effect by acid extract of ficus exasperata leaves on the sulphuric acid corrosion of mild steel," E-Journal of Chemistry, vol. 6, no. 1, pp. S189-S194, 2009.

[12] P. Kumar and A. N. Shetty, "Corrosion behaviour of $18 \% \mathrm{Ni}$ M250 grade maraging steel under welded condition in hydrochloric acid medium," Portugaliae Electrochimica Acta, vol. 31, p. 21, 2013.

[13] E.-S. M. Sherif, A. M. El Shamy, M. M. Ramla, and A. O. H. El Nazhawy, "5-(Phenyl)-4H-1,2,4-triazole-3-thiol as a corrosion inhibitor for copper in $3.5 \% \mathrm{NaCl}$ solutions," Materials Chemistry and Physics, vol. 102, no. 2-3, pp. 231-239, 2007.

[14] P. B. Raja and M. G. Sethuraman, "Natural products as corrosion inhibitor for metals in corrosive media-a review," Materials Letters, vol. 62, no. 1, pp. 113-116, 2008.

[15] K. Parameswari, S. Chitra, S. Kavitha, J. Rajpriya, and A. Selvaraj, "Adsorption and inhibitive properties of triazolopyrimidine derivatives in acid corrosion of mild steel," E-Journal of Chemistry, vol. 8, no. 3, pp. 1250-1257, 2011.

[16] C. Wang, S. Chen, and S. Zhao, "Inhibition effect of ACtreated, mixed self-assembled film of phenylthiourea and 1dodecanethiol on copper corrosion," Journal of the Electrochemical Society, vol. 151, no. 1, pp. B11-B15, 2004.

[17] X. Liu, F. Li, Q. Lu, Y. Xia, and C. Zhang, "Study of range distribution parameters for fluorine ions implantation in $\mathrm{AgGaS}_{2}$ crystal," Applied Surface Science, vol. 218, no. 1-4, pp. 138-142, 2003.

[18] G. K. Gomma and M. H. Wahdan, "Effect of temperature on the acidic dissolution of copper in the presence of amino acids," Materials Chemistry and Physics, vol. 39, no. 2, pp. 142-148, 1994.

[19] K. F. Khaled and N. Hackerman, "Ortho-substituted anilines to inhibit copper corrosion in aerated $0.5 \mathrm{M}$ hydrochloric acid," Electrochimica Acta, vol. 49, no. 3, pp. 485-495, 2004.

[20] A. Dafali, B. Hammouti, R. Touzani, S. Kertit, A. Ramdani, and K. El Kacemi, "Corrosion inhibition of copper in 3 per cent $\mathrm{NaCl}$ solution by new bipyrazolic derivatives," Anti-Corrosion Methods and Materials, vol. 49, no. 2, pp. 96-104, 2002.

[21] O. L. Riggs Jr., “Theoretical aspects of corrosion inhibitors and inhibition," in Corrosion Inhibitors, C. C. Nathan, Ed., NACE International, Houston, Tex, USA, 1973.

[22] E.-S. M. Sherif, "Corrosion behavior of duplex stainless steel alloy cathodically modified with minor ruthenium additions in concentrated sulfuric acid solutions," International Journal of Electrochemical Science, vol. 6, no. 7, pp. 2284-2298, 2011.

[23] G. Bolat, D. Mareci, S. Iacoban, N. Cimpoesu, and C. Munteanu, "The estimation of corrosion behavior of NiTi and NiTiNb alloys using dynamic electrochemical impedance spectroscopy," Journal of Spectroscopy, vol. 2013, Article ID 714920, 7 pages, 2013.

[24] F. Mansfeld, S. Lin, K. Kim, and H. Shih, "Pitting and surface modification of SIC/Al," Corrosion Science, vol. 27, no. 9, pp. 997-1000, 1987.

[25] N. Maouche and B. Nessark, "Cyclic voltammetry and impedance spectroscopy behavior studies of polyterthiophene modified electrode," International Journal of Electrochemistry, vol. 2011, Article ID 670513, 5 pages, 2011.

[26] E. Rafiee, M. Farzam, M. A. Golozar, and A. Ashrafi, "An investigation on dislocation density in cold-rolled copper using electrochemical impedance spectroscopy," ISRN Corrosion, vol. 2013, Article ID 921825, 6 pages, 2013. 
[27] E.-S. M. Sherif, A. A. Almajid, K. A. Khalil, H. Junaedi, and F. H. Latief, "Electrochemical studies on the corrosion behavior of API X65 pipeline steel in chloride solutions," International Journal of Electrochemical Science, vol. 8, p. 9360, 2013.

[28] E.-S. M. Sherif, "Effects of 2-amino-5-(ethylthio)-1,3,4-thiadiazole on copper corrosion as a corrosion inhibitor in $3 \% \mathrm{NaCl}$ solutions," Applied Surface Science, vol. 252, no. 24, pp. 86158623, 2006. 

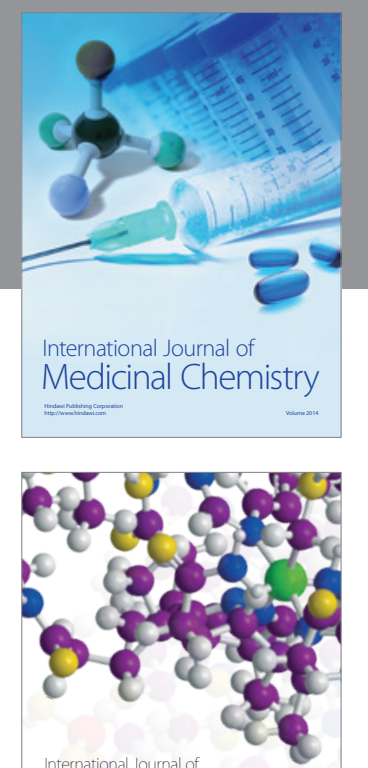

\section{Carbohydrate} Chemistry

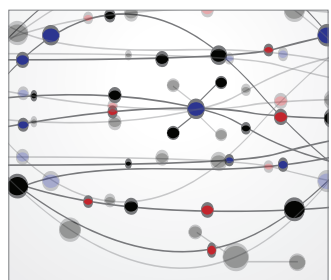

The Scientific World Journal
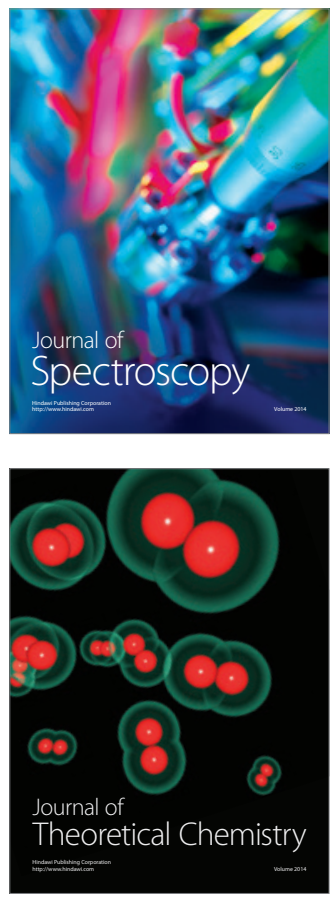
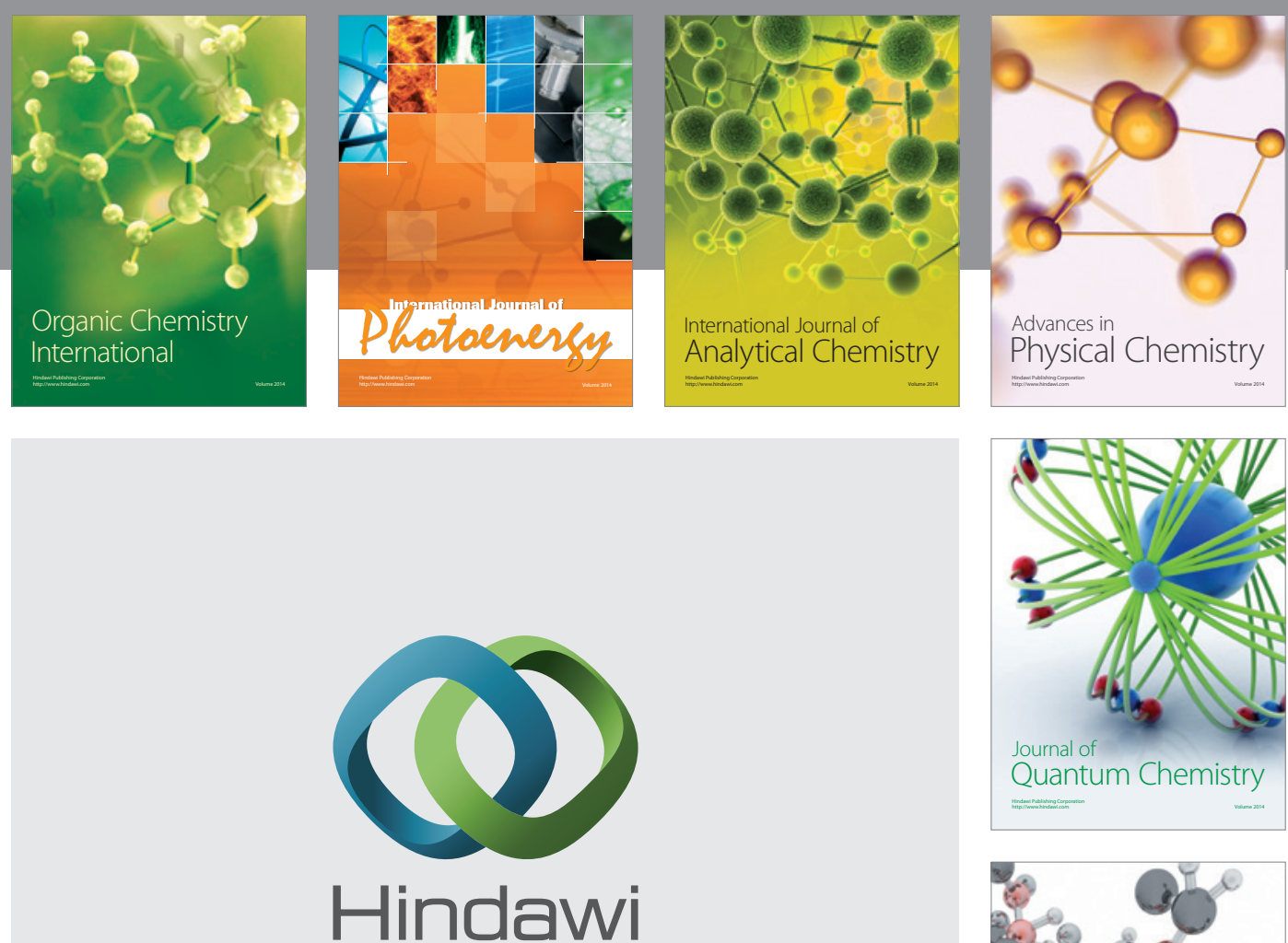

Submit your manuscripts at

http://www.hindawi.com

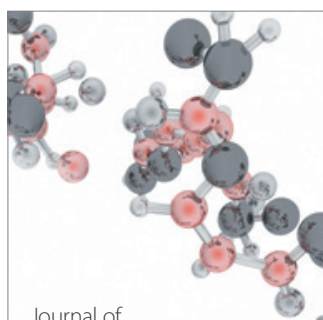

Analytical Methods

in Chemistry

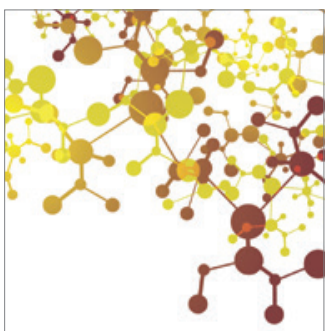

Journal of

Applied Chemistry

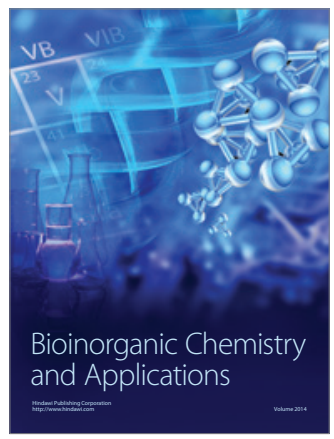

Inorganic Chemistry
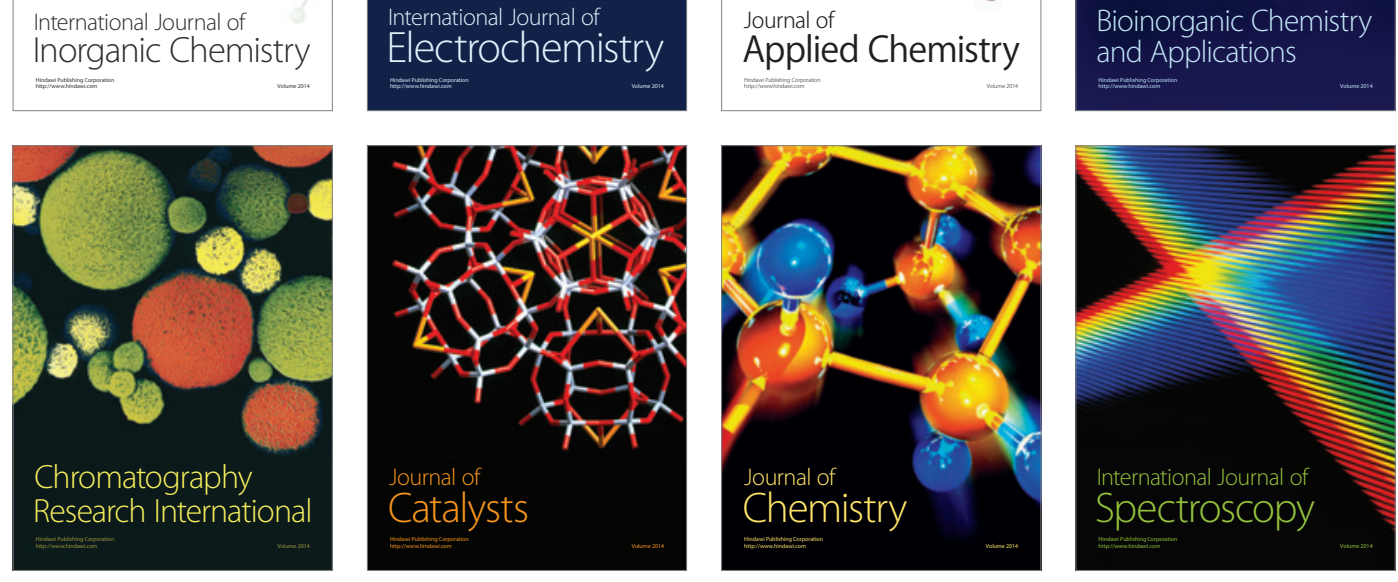